\title{
MJMR ASSESSMENT OF KNOWLEDGE AND COMPLIANCE OF CRITICAL CARE NURSES REGARDING VENTILATOR ASSOCIATED PNEUMONIA (VAP) CARE BUNDLE IN A TERTIARY CARE HOSPITAL, ASSAM
}

\author{
Chaltung Khishung Anal \\ Govt. College of Nursing, N.R.S Medical College and Hospital, Kolkata, India \\ Corresponding Author's Email: chaltungkhishung@gmail.com
}

\begin{abstract}
Background: Ventilator-associated pneumonia (VAP) is reported to be the second most common nosocomial infection and the leading cause of death from nosocomial infections in critically ill patients. The purpose of the study was to assess the knowledge and compliance of critical care nurses regarding ventilator-associated pneumonia (VAP) care bundle. Research Methods: A descriptive studywas conducted in December 2018in a tertiary care hospital, Assam. 60 Critical care nurses were selected as samples by convenient sampling technique. Structured knowledge questionnaire and compliance checklist was used for data collection. Results: The result revealed that thecritical care nurses had mean knowledge scoreof $13.7 \pm 2.3(68.5 \%)$ which indicated average knowledge score.Area wise mean knowledge score was highest in the area of Concept of VAP $(85 \%)$ and was lowest in the area of the common causative organism of VAP (45\%). Mean compliance score was $24.23 \pm 1.49(93.2 \%)$ which indicated good compliance score. The maximum compliance was found in patient positioning (98\%) and oral care (98\%) and minimum compliance was found sedation vacation and weaning trials (90\%). A weak positive relationship (0.39) was found between knowledge and compliance of the critical care nurses regarding VAP care bundle which was significant $(p<0.05)$. There was no significant association between the knowledge and the selected variables. Conclusions: The study showed various degree of deficiency among the critical care nurses in the knowledge and compliance area regarding VAP care bundle. The findings of the study have implications in the field of nursing. So, the researcher recommends that further research can be conducted to evaluate a structured teaching program on VAP care bundle, and an exploratory study can be done to identify the factors and its barriers responsible for noncompliance of VAP care bundle among the critical care nurses.
\end{abstract}

\section{Keywords: Critical Care Nurses; VAP; VAPCare Bundle; Compliance}

\section{INTRODUCTION}

With the advancing age of technology, medical care has also advanced. Use of ventilators also known as "life support" or "life-sustaining equipment" for providing mechanical ventilation is very crucial and life-saving support therapy for the critically ill and respiratory failure patients in the intensive care units (ICUs). Although it has been considered as life-saving therapy the patients are at high risk for complications and poor prognosis, including death (Esteban, Anzueto \& Frutos et al., 2002).

Ventilator-associated pneumonia (VAP) is a type of pneumonia that occurs in a patient who was intubated and ventilated at the time of or within 48 hours before the onset of pneumonia. According to the radiologic, clinical and laboratory criteria findings, it is further divided into clinical pneumonia, pneumonia with specific laboratory findings, or pneumonia in immune-compromised patients (CDC, 2018).

VAP is divided into two types, early onset VAP that occurs within 4 days and this is usually attributed to antibiotic-sensitive pathogens whereas late-onset VAP is more likely caused by multidrug-resistant (MDR) bacteria and emerges after 4 days of intubation (American thoracic society, 2005).

Among the risk factors, an endotracheal tube is the single 
largest VAP risk factor. Host or patient risk factors include the age of 65 or more, underlying chronic illness (e.g. Chronic Obstructive Pulmonary Disease, emphysema, and asthma), immune suppression, depressed consciousness, thoracic or abdominal surgery, previous antibiotic therapy, previous pneumonia or remote infection. Other devices and personnel-related risk factors include supine patient position, nasogastric tube placement, stress ulcer treatment, bolus enteral feeding, gastric over-distension, nasal intubation route, instillation of normal saline, indiscriminate use of antibiotics, understaffing, noncompliance to a standard hand washing protocol, and lack of training in VAP prevention (Hooser, 2002).

Ventilator-associated pneumonia (VAP) is reported to be the second most common nosocomial infection and the leading cause of death from nosocomial infections in critically ill patients (Torres, Niederman, Chastre, et al.,2017).The international nosocomial infection control consortium (INICC) data suggests a VAP incidence as high as 13.6/1000 mechanical ventilation (MV) days(Rosenthal, Maki \& Jamulitrat et al., 2010). The occurrence of VAP in Asian countries is much higher and ranges from 3.5 to 46 infections/1000 MV days (Chawla, 2008). In comparison to the developed countries, the incidence rate of VAP and mortality rate is much higher in the developing countries. In India, the incidence is 40.1 VAP infections/1000 mechanical ventilation days (Mathai, Phillips, Isaac, 2016).

VAP is also associated with prolonging the duration of mechanical ventilation, ICU stays, and hospital stays. VAP leads to an additional increase of more than $\$ 40,000$ health care costs for each patient (Rello, Ollendorf, Oster, et al., 2002). Therefore; prevention of VAP is the crucial part in providing quality patient care in the ICUs.

A VAP prevention bundle was developed by the Institute for Healthcare Improvement (IHI) in 2001 and updated in 2011. The bundle consists of a number of evidencebased strategies proved to prevent VAP which are the elevation of the head end of the bed, daily sedation interruption and assessment of readiness to extubate, Peptic ulcer prophylaxis, Deep vein thrombosis prophylaxis, oral hygiene with chlorhexidine (How-to Guide, 2012).

In addition, The INICC prevention bundle was developed in 2013 which describe evidence-based interventions and recommendations for VAP prevention in the ICU. The INICC prevention bundle also followed the recommendation by IHI (INICC, 2013).

VAP being a burden to the care of a patient, surveillance, guidelines, and bundles were published and implemented in an attempt to reduce the rate of VAP and indeed resulted in the reducing morbidity and mortality of VAP.

Several studies were conducted to find out the application of the VAP bundle and its impact on the incidence rate of VAP in the ICU. The findings revealed reduced in the incidence rate of VAP after the bundle application (Al-Abdely, Mohammed, Rosenthal et al., 2018 \& Bukhari, Hussain, Banjar, et al., 2012).

The researcher had observed during personal working experiences that incidence of VAP is high in ICU patients, prolonging their ICU and hospital stay and increasing their treatment cost as well. Nurses as a holistic caregiver of the patient and who stays 24 hours beside the patient, awareness and up-to-date knowledge of regarding VAP and its prevention bundle is very important and not only that but strict adherence to the VAP bundle is necessary to prevent VAP. Nurses' lack of knowledge may be a barrier to adhere to VAP bundle guidelines for preventing ventilator-associated pneumonia Therefore this study is aimed at examining critical care nurses' knowledge and compliance to ventilator-associated pneumonia (VAP) care bundle to prevent VAP in a tertiary care hospital.

\section{METHODOLOGY}

Research Design: A descriptive survey design was adopted for this study to collect information from selected sixty critical care nurses within a given population having same characteristics of interest to observe and document the knowledge and compliance related to ventilator-associated pneumonia (VAP) care bundle in its natural setting without any manipulation or control.

Setting of the Study: The study was conducted in Apollo hospitals, unit: international hospitals, Guwahati, Assam

\section{Sample, Sampling Technique, Sample Size}

- Sample: Critical care nurses working in the critical care units of Apollo hospitals, unit: international hospital, Guwahati, Assam.

- Sampling Technique: Nonprobability convenient sampling technique. 
- Sample Size: 60 critical care nurses who were working at the time of data collection at Apollo hospitals, unit: international hospital, Guwahati, Assam.

Data Collection Tool and Techniques: The data collection was done by a structured tool consisting of 3 parts.Part A: Semi- structured questionnaire for demographic Proformawas collected by paper pencil technique, Part B Structured knowledge questionnaire on VAP care bundle was collected by paper pencil technique and Part C Structured compliance checklist on VAP care bundlewas collected by Observation and record analysis.

Ethical Approval: Approval to conduct this research study was granted by Principal of Govt. College of Nursing, N.R.S.M.C\&H, Kolkata, ethical and scientific committee of N.R.S.M.C\&H, Kolkata. Directorate and Joint Director Health Services, West Bengal and Dean, Faculty of Dental Science, W. B. U. H. S., Director of Apollo hospitals, unit: international hospital, Guwahati, Assam and Informed consent was taken from participant.

Plan for Data Analysis: The collected data was edited, compiled, and analyzed by using both descriptive and inferential statistics.

\section{RESULTS}

Result of analysis of obtained data was organized and presented under the following sections:

Section I: Demographic Data for Determining Sample Characteristics: Demographic characteristicsas shown in Table 1

Table 1: Frequency and Percentage Distribution of Critical Care Nurses in Terms of Demographic Data $(n=60)$

\begin{tabular}{|l|c|c|c|}
\hline Serial no. & Sample Characteristics & Frequency & Percent (\%) \\
\hline 1 & Age in years & & \\
& $20-24$ & 15 & 25 \\
& $25-29$ & 36 & 60 \\
& $30-34$ & 8 & 13 \\
& $35-40$ & 1 & 2 \\
\hline 2 & Gender & & \\
& Female & 60 & 100 \\
\hline
\end{tabular}

Majority of the critical care nurses $37(62 \%)$ had an experience in ICU of less than 2 years and only $2(3 \%)$ critical care nurses had more than six years of experience. Further data revealed that majority of the critical care nurses $34(57 \%)$ had total years of professional experience were less than 3 years and only $1(2 \%)$ critical care nurse had more than nine years of professional experience. See Table 2

Table 2: Frequency and Percentage Distribution of Critical Care Nurses in Terms of Demographic Data $(n=60)$

\begin{tabular}{|l|c|c|c|}
\hline Serial no. & Sample characteristics & Frequency & Percent (\%) \\
\hline 1 & Years of experience in ICU & & \\
& $<2$ & 37 & 62 \\
& $2-4$ & 17 & 28 \\
& $4-6$ & 2 & 7 \\
& $>6$ & & 3 \\
\hline 2 & Total years of professional & & \\
& experience & 34 & 57 \\
& $<3$ & 22 & 36 \\
& $3-6$ & 3 & 5 \\
& $6-9$ & 1 & 2 \\
\hline
\end{tabular}

Majority of the critical care nurses $41(68 \%)$ had qualification of GNM nursing and 19 (32\%) nurses with B.Sc. nursing. See figure 1

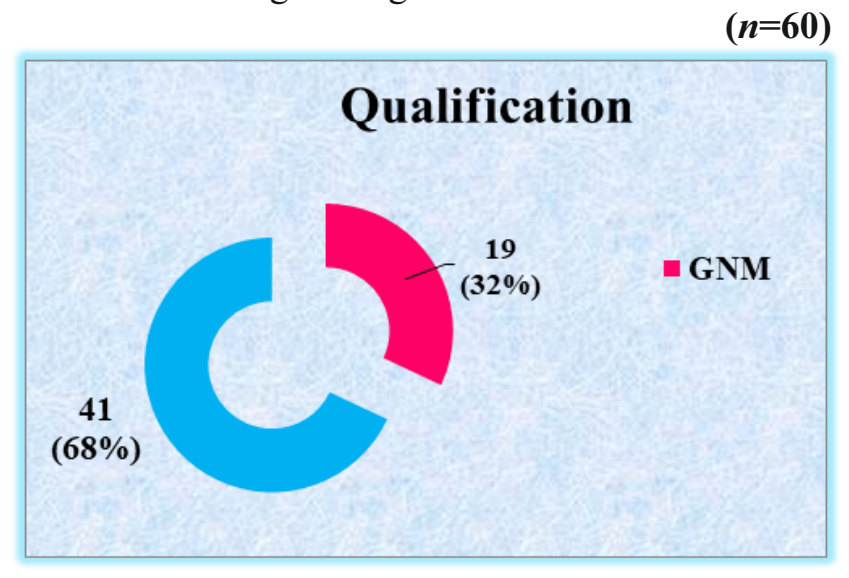

Figure 1:Doughnut Diagram Showing Percentage Distribution of Critical Care Nurses Based on Their Qualification. $(n=60)$

Maximum 32 (54\%) of the critical care nurses were working in ICU whereas minimum $8(13 \%)$ in the SICU, See figure 2 
$(n=60) \quad$ Section II: Findings Related to the Knowledge Scores

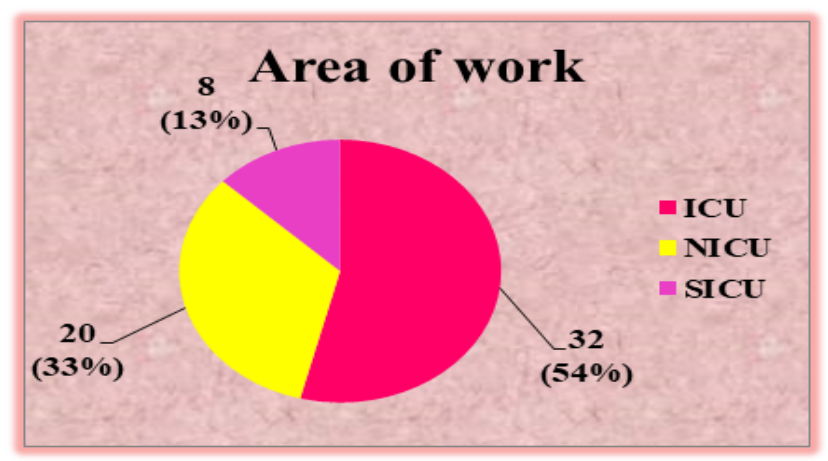

Figure 2: Pie Diagram Showing Percentage Distribution of Critical Care Nurses According to Their Area of Work.

$(n=60)$

Majority of the critical care nurses $33(55 \%)$ had attended programme on VAP care bundle and $27(45 \%)$ did not attended any training programme or workshop attended on VAP care bundle. See figure 3

$$
(n=60)
$$

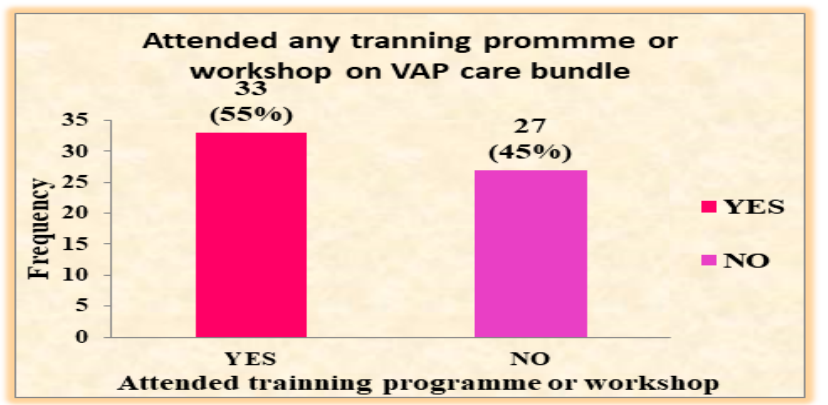

Figure 3: Bar Diagram Showing the Percentage Distribution of Critical Nurses According to Any Training Programmeor Workshop Attended on VAP Care Bundle.

$(n=60)$

Majority of the critical care nurses 53(88\%) were aware of VAP statistics in their hospital and $7(12 \%)$ were not aware of VAP rate in their hospital. See figure 4

$(n=60)$

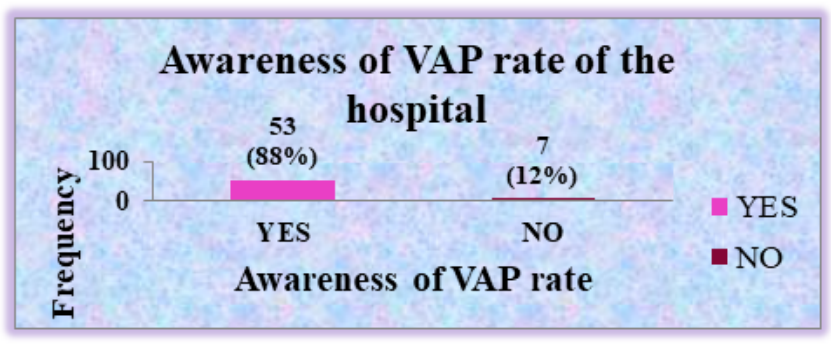

Figure 4: Bar Diagram Showing the Percentage Distribution of Critical Care Nurses According to the Awareness of VAP Rate of the Hospital. of Critical Care Nurses Regarding VAP Care Bundle:

The knowledge score of the critical care nurses ranged from 9-19, where maximum possible score was 20 and mean knowledge score was 13.7; median was 13.5 with $\mathrm{SD}$ of 2.3. The mean percentage of knowledge score was $68.5 \%$ which indicated average level of knowledge as the level of knowledge was classified as below 50\% referred as poor, $50 \%-75 \%$ as average and $>75 \%$ was referred as good level of knowledge. See Table 3

Table 3: Mean, Median, SD and Mean Percentage of knowledge Scores of the Critical Care Nurses Regarding Vap Care Bundle.

$(n=60)$

\begin{tabular}{|l|c|c|c|c|c|}
\hline Variable & $\begin{array}{c}\text { Obtained } \\
\text { range score }\end{array}$ & Mean & Median & SD & $\begin{array}{c}\text { Mean percent } \\
(\mathbf{\%})\end{array}$ \\
\hline Knowledgescores & $9-19$ & 13.7 & 13.5 & 2.3 & 68.5 \\
\hline
\end{tabular}

\section{Maximum score $=20$, Minimum score $=0$}

Maximum mean percentage score was gained by critical care nurses in area of Concept of VAP (85\%) indicated that a good knowledge existed in this area whereas the minimum mean percentage of score was in the area of Common causative organism of VAP (45\%) which indicated that average knowledge existed in this area.See Table 4

Table 4: Area Wise Maximum Possible Score, Mean, SD and Mean Percentage of Knowledge Score Obtained by the Critical Care Nurses on Structured Knowledge Questionnaire.

$(n=60)$

\begin{tabular}{|l|c|c|c|c|c|}
\hline $\begin{array}{l}\text { Serial } \\
\text { no. }\end{array}$ & Areas & $\begin{array}{c}\text { Maximum } \\
\text { Possible score }\end{array}$ & Mean score & SD & $\begin{array}{c}\text { Mean percent } \\
\text { (\%) }\end{array}$ \\
\hline 1 & Concept of VAP & 2 & 1.7 & 0.49 & 85 \\
\hline 2 & $\begin{array}{c}\text { Common causative } \\
\text { organism of VAP }\end{array}$ & 1 & 0.45 & 0.50 & 45 \\
\hline 3 & Risk factors of VAP & 3 & 2.1 & 0.65 & 70 \\
\hline 4 & $\begin{array}{c}\text { VAP prevention care } \\
\text { bundle }\end{array}$ & 14 & 9.5 & 1.69 & 67.9 \\
\hline
\end{tabular}

Section III: Findings Related to the Compliance Scores of Critical Care Nurses Regarding VAP Care Bundle:

The compliance score of the critical care nurses ranged from 20-26, where maximum possible score was 26 and mean compliance score was 24.23; median was 24 with $\mathrm{SD}$ of 1.49 . The mean percentage of compliance score was $93.2 \%$ which indicated good level of compliance as the level of compliance was classified as below 50\% referred as poor, $50 \%-75 \%$ as average and $>75 \%$ was 
referred as good level of compliance. See Table 5

Table 5: Mean, Median, SD and Mean Percentage of Compliance Scores of Critical Care Nurses Regarding VAPCare Bundle

$(n=60)$

\begin{tabular}{|l|c|c|c|c|c|}
\hline Variable & $\begin{array}{c}\text { Obtained } \\
\text { range score }\end{array}$ & Mean & Median & SD & $\begin{array}{c}\text { Mean percent } \\
\text { (\%) }\end{array}$ \\
\hline $\begin{array}{l}\text { Compliance } \\
\text { scores }\end{array}$ & $20-26$ & 24.23 & 24 & 1.49 & 93.2 \\
\hline
\end{tabular}

Maximum score $=26$, Minimum score $=0$

According to the area wise,maximum mean percentage score gained by critical care nurses was in area of oral care $(98 \%)$ and patient positioning $(98 \%)$ whereas the lowest mean percentage of score was in the area of sedation vacation and weaning trials (90\%). See Table 6

Table 6: Area Wise Maximum Possible Score, Mean, $S D$ and Mean Percentage of Compliance Score Obtained by the Critical Care Nurses on Structured Compliance Checklist.

$(n=60)$

\begin{tabular}{|l|c|c|c|c|c|}
\hline $\begin{array}{l}\text { Serial } \\
\text { no. }\end{array}$ & Areas & $\begin{array}{c}\text { Maximum } \\
\text { possible score }\end{array}$ & $\begin{array}{c}\text { Mean } \\
\text { score }\end{array}$ & SD & $\begin{array}{c}\text { Mean } \\
\text { percent } \\
\text { (\%) }\end{array}$ \\
\hline 1 & Hand hygiene & 6 & 5.53 & 0.69 & 92.2 \\
\hline 2 & Patient positioning & 1 & 0.98 & 0.13 & 98 \\
\hline 3 & Ventilator care measures & 5 & 4.67 & 0.60 & 93.4 \\
\hline 4 & Tracheal suction care & 7 & 6.5 & 0.67 & 92.9 \\
\hline 5 & Oral care & 1 & 0.98 & 0.13 & 98 \\
\hline 6 & $\begin{array}{c}\text { Peptic ulcer disease } \\
\text { prophylaxis }\end{array}$ & 2 & 1.92 & 0.30 & 95.5 \\
\hline 7 & $\begin{array}{c}\text { Deep vein thrombosis } \\
\text { prophylaxis }\end{array}$ & 1 & 0.95 & 0.22 & 95 \\
\hline 8 & $\begin{array}{c}\text { Sedation vacation and } \\
\text { weaning trials }\end{array}$ & 3 & 2.7 & 0.50 & 90 \\
\hline
\end{tabular}

Section IV: Findings Related to the Relationship Between Knowledge and Compliance of Critical Care Nurses Regarding VAP Care Bundle:

A weak positive correlation (0.39) was established between the knowledge and compliance scores. It was found that the calculated " $t$ " value of " $r$ " was 3.22 which was significant at 0.05 level of significance with 58 degree of freedom and it was higher than the tabulated value 0.250 . So, there was a statistically significant relationship between knowledge score and compliance regarding VAP care bundle see Table 7.

Table 7: Relationship Between Knowledge Score and Compliance Score of Critical Care Nurses Regarding VAPCare Bundle

$(n=60)$

\begin{tabular}{|l|c|c|}
\hline Variable & “ $\boldsymbol{r}$ " value & " $\boldsymbol{t}$ ” value \\
\hline $\begin{array}{l}\text { Knowledge and compliance of the critical } \\
\text { care nurses regarding VAP care bundle }\end{array}$ & 0.39 & $3.22 *$ \\
\hline
\end{tabular}

$t^{\prime} d f(58)=0.250, p<0.05$
Section V: Findings Related to Association of Knowledge With the Selected Variables: The calculated chi-square value was less than tabulated value at 0.05 level of significance with one degree of freedom for association with Age, Qualification, Years of experience in ICU, Area of work, Total years of professional experience, attended any training programme or workshop on VAP care bundle, and the Awareness of VAP rate of the hospital. Thus, there was no significant association between the knowledge score with selected demographic variables. See table 8

Table 8: Association Between Knowledge of Critical Care Nurses Regarding Critical Care Nurses (<median and >median) and the Selected Demographic Variables

$(n=60)$

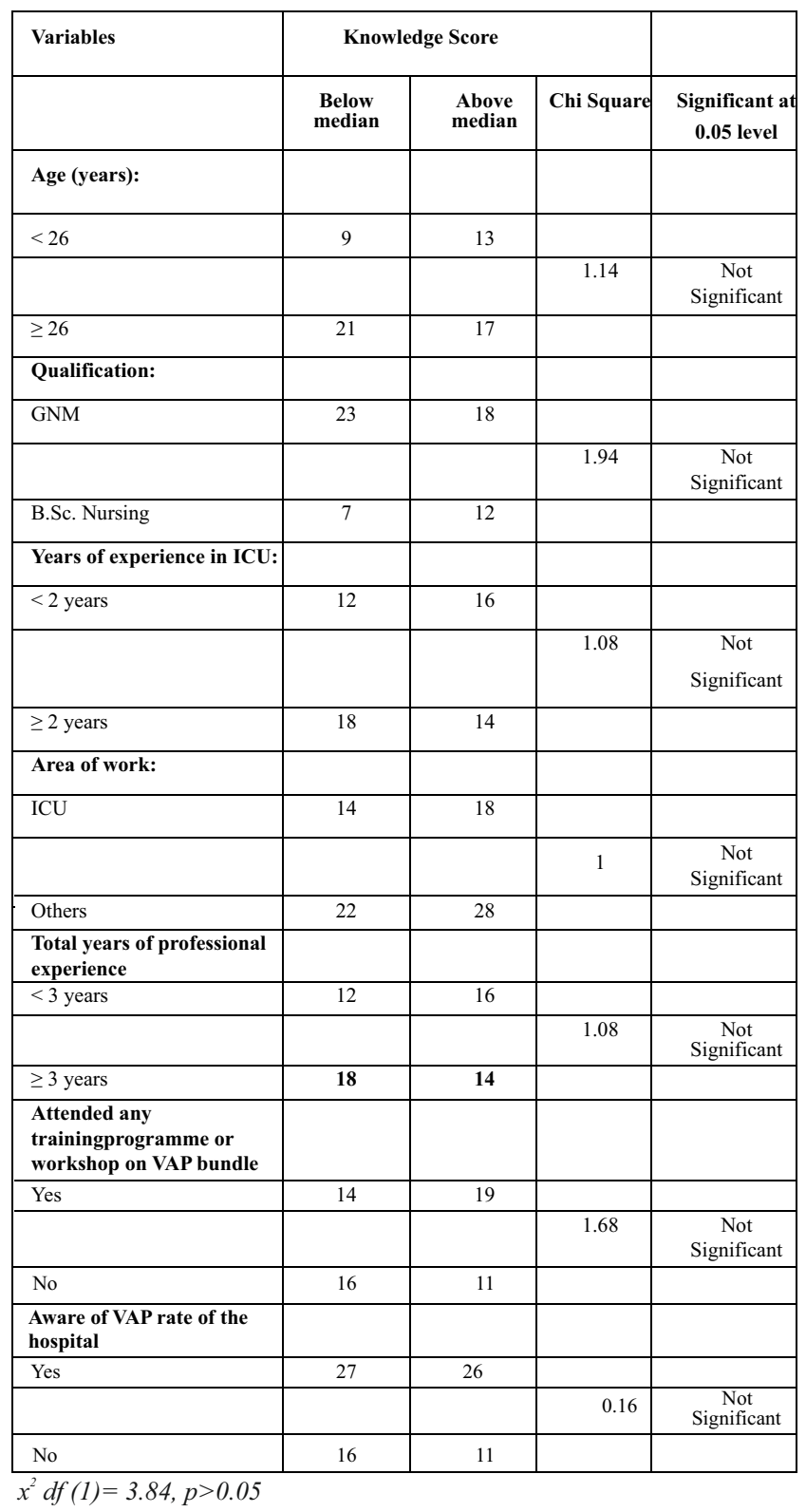




\section{DISCUSSION}

A similar type of study was conducted by Al Shameri FA in 2015 with the aim to evaluate critical care nurse's knowledge regarding VAP prevention among 120 nurses in Sudan. The findings showed that with regards to the age, majority of the participant's age between 23 30 years old, (71.7\%) were female, and (86.7\%) had a bachelor's degree, with (47.6\%) had less than 1 year of experience. The study showed overall knowledge of nurses regarding the VAP prevention mean was (18.22 from 40) that is a poor result which shows us that most of the nurses have inadequate knowledge about VAP prevention (Al Shameri, 2017).

Another similar study was conducted by Silva Sabrina Guterres da et al., in 2014, Santa Catarina. It aimed at evaluating compliance with a bundle to prevent ventilator-associated pneumonia in an Intensive Care Unit. The sample consisted of 1,146 observations of the four elements that compose the bundle (head of bed elevation between $30-45^{\circ}$; endotracheal suctioning; cuff pressure between $20-30 \mathrm{cmH} 2 \mathrm{O}$; and oral care with $0.12 \%$ chlorohexidine). The study showed overall bundle compliance of 794 (69.2\%), of which compliance of oral care and suctioning $(84.7 \%)$, the elevation of the head end of the bed had the lowest compliance (55.5\%) and cuff pressure (61.8\%)(Silva Sabrina Guterres da et al., 2014).

The assumption of the study was Critical care nurses will have adequate knowledge regarding ventilatorassociated pneumonia (VAP) care bundle and the finding of the study showed the mean percentage of knowledge score was $68.5 \%$ which indicated average level of knowledge. However, the study has some limitations. First, this study was a descriptive study, with a small size of the sample (60) selected by nonprobability convenience sampling and confined to a specific area (critical care units) which implies limits on scope of generalization. Moreover, it was conducted in the private hospital setting.

\section{CONCLUSION}

Ventilator associated pneumonia is a commonest hospital acquired infection in the intensive care units in the hospital. Nurses as a holistic caregiver of the patient and also being the personnel who stays beside the patient for 24 hours, it is crucial for the nurses to stay aware and updated towards various preventive bundles against infection. The present study showed various degree of deficiency among the critical care nurses in the knowledge and practice area regarding VAP care bundle. The findings of this data have implications for Nursing practice, Nursing Education, Nursing Administration, and Nursing Research. It highlights the need for special trainingprogram meregarding VAP care bundle. Maintenance of nurse-patient ratio and adequate supply of articles in the unit is also essential for the compliance to the VAP care bundle.

The following recommendations were drawn based on the findings of the study.

o A study can be done to evaluate the structured teaching program on VAP care bundle among the critical care nurses

o A similar study can be replicated on a larger sample covering the entire nursing personnel in hospital as well as other parts of the country for validation and generalization.

o A comparative study can be carried out between nursing personnel of government and private hospitals.

o An exploratory study can be done to identify the factors and its barriers responsible for noncompliance of VAP care bundle.

o A similar study can be done with an experimental research approach

\section{Conflict of Interest}

The author declares that they have no conflict of interest.

\section{ACKNOWLEDGEMENT}

First and foremost, I am very thankful to the Almighty God for blessing me with good health throughout my study and helping me to complete this work. I would like to give my sincere gratitude to my respected guide Prof. Ranu Bag, Principal, Govt. College of Nursing, N.R.S. Medical College \& Hospital, Kolkata for her constant support, valued guidance and suggestions at each stage of preparation of my research study. I express my special thanks to my parents Chaltung Rungam Anal and Wanglum Hringtang Anal and my sweet sisters for their love and support throughout the study.

Last but not the least, I give my special thanks to all the critical care nurses who were a part of this study for placing their trust and cooperation with me during the study. 


\section{REFERENCES}

Al-Abdely, H.M., Mohammed, Y.K., Rosenthal, V.D., Orellano, P.W., ALazhary, M., Kaid, E., Al-Attas, A., Hawsawi, G., Kelany, A., Hussein, B. and Esam, B., Altowerqi,R., Alkamaly, M.A., Tawfic, N.A., Cruzpero, E., Al Rashidi, R.M., Thomas, R., Molano, A.M., Al Enazy, H.A., Al Adwani, F.M., Pahilanga, A.M.C., Alatawi, S., Nakhla, R., Al Adwani, F.M., Aromin, R.G., Ubalde, E.B., Diab, H.H., Kader, N.A., Assiry, I.Y.H., Sawan, F.A., Ammari, H.E., Mashiakhy, A.M., Santiago, E.B., Chua, C.M.S., Dalis,I.M., Arishi,H.M., Lozada,R., Asiri, I.A.M.A., Ahmed,H., Jarie, A., Al-Qathani, A.S.M., Al-Alkami,H.Y., AlDalaton, M., Alih,S.J.B., Alaliany,M.J., Helali,N.J.,Sindayen,G., Malificio,A.A., Al Dossari,H.B., Algethami,A.G., Mohamed,D.., Yanne,L., Tan,A., Babu,S., Abduljabbar,S.M., Rushdi,H., Fernandez,J., Hussain,W.M., Rajavel,R.D., Bukhari,S.Z., Turkistani,A.A., Mushtaq, J.J., Albeladi,E., Aboushoushah,S., Qushmaq, N., Shyrine,L., Philipose,J., Raees, M., AbdulKhalik,N.S., Madco, M., Abdulghany, M., Manao,A., Acostan, C., Safwat, R., Halwani, M., Aal, N.A.H.A., Thomas, A., Abdulatif, S.M., Ariola, N.C., Mutwalli, A.H., Ariola, N., Bohlega, E., Simon, S., Damlig, E., Elsherbini, S.G., Krishne, I.T., Abraham, S., Karrar, M.A.A., Gosn. N.A., Al Hindi, A.A., Jaha, R.N., AlQahtani, S.M.,Aziz, A.O.A., Demaisip, N.L., Cortez, E.L.,Cabato, A.F., Celiz, J.M.G., Al Raey, M.A., Al Darani, S.A., Aziz, M.R, Manea, B.A., Samy, E., Briones, S., Krishnan, R., Raees, S.S.M., Tabassum, K., Ghalilah, K.M., Alradady, M., Al Qatri, A., Chaouali, M., Elsisi, M., Aldossary, H.A., Al-Suliman, S., Al Talib, A.A., Albaghly, N., Mia, M.E.H., Al-Gethamy, M.M., Alamri, D.M., AlSaadi, A.S., Ayugat, E.P., Al Hazazi, N.A., Al Hussain, M.I., Caminade, Y., Santos, A.J., Abdulwahab, M. \& Al-Garni, B.T.A. (2018). Impact of the International Nosocomial Infection Control Consortium (INICC)'s multidimensional approach on rates of ventilator-associated pneumonia in intensive care units in 22 hospitals of 14 cities of the Kingdom of Saudi Arabia. Journl of Infection and Public Health. Sep-Oct, 11(5):677-684.

Al Shameri, F.A. 2017. Critical care nurse's knowledge of ventilator-associated pneumonia prevention in selected hospitals, khartoum. Nursing \& Healthcare International Journal, 1(5), pp.1-7.
American Thoracic Society and Infectious Diseases Society of America, (2005). Guidelines for the management of adults with hospital-acquired, ventilator-associated, and healthcare-associated pneumonia. American Journal of Respiratory and Critical Care Medicine, 171(4), p.388.

Bukhari, S.Z., Hussain, W.M., Banjar, A.A., Fatani, M.I., Karima, T.M. \&Ashshi, A.M., 2012. Application of ventilator care bundle and its impact on ventilator associated pneumonia incidence rate in the adult intensive care unit. Saudi Med J, 33(3), pp.278-283.

Chawla, R., (2008). Epidemiology, etiology, and diagnosis of hospital-acquired pneumonia and ventilator-associated pneumonia in Asian countries. American Journal of Infection control, 36(4), pp. S93-S100.

Esteban, A., Anzueto, A., Frutos, F., Alía, I., Brochard, L., Stewart, T.E., Benito, S., Epstein, S.K., Apezteguía, C., Nightingale, P. \& Arroliga, A.C., (2002). Characteristics and outcomes in adult patients receiving mechanical ventilation: a 28-day international study. Jama, 287(3), pp.345-355.

Guide, H.T., (2012). Prevent ventilator-associated pneumonia. Cambridge, MA: Institute for Healthcare Improvement. Retrieved from:http:// www.ihi.org/resources/Pages/Tools/Howto GuidePrevent VAP.aspx

Mathai, A.S., Phillips, A. and Isaac, R., (2016). Ventilator-associated pneumonia: A persistent healthcare problem in Indian Intensive Care Units! Lung India: Official Organ of Indian Chest Society, 33(5), p.512.

Rello, J., Ollendorf, D.A., Oster, G., Vera-Llonch, M., Bellm, L., Redman, R. \& Kollef, M.H., 2002. Epidemiology and outcomes of ventilatorassociated pneumonia in a large US database. Chest, 122(6),pp.2115-2121.

Rosenthal, V. D., Maki, D. G., Jamulitrat, S., Medeiros, E. A., Todi, S. K., Gomez, D. Y., Leblebicioglu, H., Abu Khader, I., Miranda Novales, M. G., Berba, R., Ramírez Wong, F. M., Barkat, A., Pino, O. R., Dueñas, L., Mitrev, Z., Bijie, H., Gurskis, V., Kanj, S. S., Mapp, T., Hidalgo, R. F., INICC Members (2010). International Nosocomial Infection Control Consortium (INICC) report, data summary for 2003-2008, issued June 2009. American Journal of Infection Control, 38(2), 95-104.e2. 
Silva, S.G.D., Salles, R.K.D., Nascimento, E.R.P.D., Bertoncello, K.C.G. \& Cavalcanti, C.D. (2014). Evaluation of a bundle to prevent ventilatorassociated pneumonia in an intensive care unit. Texto \& Contexto-Enfermagem, 23(3), pp.744-750.

The International Nosocomial Infection Control Consortium (INICC). (2013). Retrieved from: www.INICC.org.

Torres, A., Niederman, M. S., Chastre, J., Ewig, S., Fernandez-Vandellos, P., Hanberger, H., Kollef, M., Li Bassi, G., Luna, C. M., Martin-Loeches, I., Paiva, J. A., Read, R. C., Rigau, D., Timsit, J. F., Welte, T., \&Wunderink, R. (20 1 7 ). International ERS/ESICM/ESCMID/ALAT guidelines for the management of hospital-acquired pneumonia and ventilator-associated pneumonia: Guidelines for the management of hospital-acquired pneumonia (HAP)/ventilator-associated pneumonia (VAP) of the European Respiratory Society (ERS), European Society of Intensive Care Medicine (ESICM), European Society of Clinical Microbiology and Infectious Diseases (ESCMID) and Asociación Latinoamericana del Tórax (ALAT). The European Respiratory Journal, 50(3), 1700582.

Van Hooser, D.T. (2002). Ventilator-associated pneumonia (VAP) best practice strategies for caregivers. Kimberly-Clark Corporation, Roswell, GA USA. Retrieved from:https://pt.halyardhealth. com/media/1488/vap_ceu_booklet_z0406.pdf 